\title{
ON THE ESSENTIAL SPECTRA OF UNBOUNDED OPERATOR MATRICES WITH NON DIAGONAL DOMAIN AND AN APPLICATION
}

\author{
Marwa Belghith, Nedra Moalla And Ines Walha
}

\begin{abstract}
This paper is devoted to the investigation of the spectral stability of unbounded operator matrices with non diagonal domain in product of Banach spaces. Our results are aimed to characterize some essential spectra of this kind of operators in terms of the union of the essential spectra of the restriction of its diagonal operators entries. The abstract results are illustrated by an example of two-group transport equations with perfect periodic boundary conditions.
\end{abstract}

Mathematics subject classification (2010): 47A10, 47A53, 34K08.

Keywords and phrases: Operator matrices, perturbation theory for Fredholm operators, essential spectra, transport operator, perfect periodic boundary conditions.

\section{REFERENCES}

[1] F. V. Atkinson, H. Langer, R. Mennicken and A. A. Shkalikov, The essential spectrum of some matrix operators, Math. Nachr. 167 (1994), 5-20.

[2] A. Batkai, P. Binding, A. Dijksma, R. Hryniv, AND H. LANGer, Spectral problems for operator matrices, Math. Nachr. 278 (2005), 1408-1429.

[3] A. Ben Ali And N. Moalla, Fredholm perturbation theory and some essential spectra in Banach algebra with respect to subalgebra, doi.org/10.1016/j.indag., (2016).

[4] R. Dautray And J. L. Lions, Analyse mathématique et calcul numérique, Masson, Paris 9 (1988).

[5] R. Dautray And J. L. Lions, Mathematical Analysis and Numerical Methods for Science and Technology, Volume 6: Evolution Problems II, Berlin, Springer, (1999).

[6] I. C. Gohberg, A. S. Markus, I. A. Feldman, Normally solvable operators and ideals associated with them, Amer. Math. Soc. Transl., Ser. 2, 61 (1967), 63-84.

[7] S. GolDBERG, Unbounded operators, New York: Graw-Hill, (1966).

[8] G. Greiner, Perturbing the boundary conditions of a generator, Houston J. Math. 13 (1987), 213229.

[9] A. Grothendieck, Sur les applications linéaires faiblement compactes d'éspaces du type $C(K)$, Canad. J. Math. 5 (1953), 129-173.

[10] A. JERIBI, Some remarks on the Schechter essential spectra and applications to transport equations, J. Math. Anal. Appl. 275 (2002), 222-237.

[11] A. JERIBI, Spectral theory and applications of linear operators and block operator matrices, SpingerVerlag, New-York, (2015).

[12] A. JERIBI AND N. MoAlla, Fredholm operators and Riesz theory for polynomially compact operators, Acta. Appl. Math. 90 (2006), 227-245.

[13] A. JeRibi, N. MoAlla AND I. WALHA, Spectra of some block operator matrices and application to transport operators, J. Math. Anal. Appl. 351 (2009), 315-325.

[14] A. Jeribi, N. Moalla And S. Yengui, S-essential spectra and application to an example of transport operators, Math. Meth. Appl. Sci. doi.org/10.1002/mma.1564, (2012).

[15] A. Jeribi, N. Moalla And S. Yengui, Some results on perturbation theory of matrix operators, M-essential spectra and application to an example of transport operators, http://arxiv.org/licenses/nonexclusive-distrib/1.0/. 
[16] A. Jeribi AND I. Walha, Gustafson, Weidmann, Kato, Wolf, Schechter and Browder essential spectra of some matrix operator and application to a two-group transport equations, Math. Nachr. 284, no. 1, doi .org/10.1002/mana. 200710125 (2011), 67-86.

[17] T. KATO, Perturbation theory for nullity deficiency other quantities of linear operators, J. Anal. Math. 6 (1958), 261-322.

[18] K. LATRACH, Compactness properties for linear transport operator with abstract bondary conditions with slab geometry, Transport Theory statist. Phys. 22 (1993), 39-65.

[19] K. Latrach And A. DeHICI, Fredholm, semi-Fredholm perturbations and essential spectra, J. Math. Anal. Appl. 259 (2001), 227-301.

[20] K. LATRACH AND A. DEHICI, Relatively strictly singular perturbations, essential spectra and application, J. Math. Anal. Appl. 252 (2000), 767-789.

[21] V. D. MiL'man, Some properties of strictly singular operators, Func. Anal. and Its Appl. 3 (1969), 77-78.

[22] N. Moalla, M. Dammak AND A. JeRIBI, Essential spectra of some matrix operators and application to two-group Transport operators with general boundary condition, J. Math. Anal. Appl. 2, 323 (2006), 1071-1090.

[23] M. Mokhtar-Kharroubi, Time asymptotic behaviour and compactness in neutron transport theory, Euro. Jour. Mech. B Fluid, 11 (1992), 39-68.

[24] V. MÜLLER, Spectral theory of linear operator and spectral system in Banach algebras, Oper. Theo. Advances and Appl. 139 (2003).

[25] R. NAGEL, The spectrum of unbounded operator matrices with non-diagonal domain, J. Funct. Anal. 89 (1990), 291-302.

[26] A. PelCZYNS KI, On strictly singular and strictly cosingular operators. I. Strictlly singular and cosingular operators on $C(\Omega)$ spaces, Bull. Acad. Polo. Sci, Sér. Sci. Math. Astronom. Phys. 13 (1965), 31-36.

[27] R. S. Phillips, On linear transformations, Trans. Amer. Math. Soc. 48 (1940), 516-541.

[28] J. QI AND S. CHEN, Essential spectra of singular matrix differential operators of mixed order, J. Differ. Equ. 250, 13 (2011), 4219-4235.

[29] A. A. ShKalikov, On the essential spectrum of matrix operators, Math. Notes 58 (1995), 945-949.

[30] L. WeIS, On perturbations of Fredholm operators in $L_{p}(\mu)$-spaces, Proceeding of the Amer. Math. Soc. 67 (1977), 287-292.

[31] R. J. Whitley, Strictly singular operators and their conjugates, Transactions of the Amer. Math. Soc. 113 (1964), 252-261. 